\title{
Neural Networks in Crashworthiness Analysis of Thin-Walled Profile with Foam Filling
}

\author{
Michał Rogala ${ }^{1}$ \\ 1 Department of Mechanical Engineering, Lublin University of Technology, Lublin, Poland \\ e-mail:michal.rogala@pollub.edu.pl
}

\begin{abstract}
This article presents the numerical tests of thin-walled compressed columns with a square cross-section. The crush efficiency indicators were determined using the finite element method (Abaqus) and neural networks of MLP. The models had a constant circular trigger, with a diameter of $32 \mathrm{~mm}$. During dynamic analysis, the samples were loaded with $1700 \mathrm{~J}$. The numerical models were filled with aluminum foam from $40 \mathrm{~mm}$ to $180 \mathrm{~mm}$ every $20 \mathrm{~mm}$. The study presents the conclusions for the thin-walled models with crushable foam.
\end{abstract}

Keywords: energy dissipation, thin-walled structure, aluminium foam, energy absorption

\section{INTRODUCTION}

Due to the constant increase in the mechanisation of human life, passive safety is an important aspect. Designers are constantly improving the components of motor vehicles in order to enhance their ability to absorb energy. The supporting elements, as well as the body of the vehicle are designed to absorb the greatest amount of energy. An important structural component of the vehicle is the energy absorber at the connection between the longitudinal and the front Belt $[2,14]$. It usually takes a square or rectangular shape. This component absorbs a significant part of the energy during a frontal impact, particularly in the $15-20 \mathrm{~km} / \mathrm{h}$ range [4]. During the design of energy absorbers, two important principles must be taken into account. A thin-walled element should absorb as much energy as possible while being shortened for a long time, so as not to generate large overloads [3,9]. The crash-boxes, due to their application, adopt different cross-sections, e.g. square, round, omega $[8,10,17]$. The first publications describing the course of the crushing of thin-walled profiles were presented in the 1980s. Wierzbicki and Abramowicz were involved in the experimental research on square and round aluminium profiles $[1,14]$. Triggers were used with a view to gain better control over the process of crushing $[7,13]$. In order to increase the energetic efficiency of thin-walled profiles, various types of fillings have been used. In the beginning, the energy absorbers were filled with additional walls inside the profile, which increased the stiffness of the element in the direction of impact [21]. This allowed to absorb more energy, but at the same time increased the maximum force during the crushing process [19]. The filling is characterized by a similar behavior is the honeycomb, as multicell increases the amount of energy absorbed by additional planes inside the profile $[11,16]$. Another type of reinforcement of thin-walled structures is the use of foam filling [6]. In terms of their structure, foam material models can be divided into open and closed pores. This material, through its porous structure, allows absorbing additional energy [15]. Neural networks are often used for analysis due to the large amounts of data and the multitude of relationships between them [5]. Multilayer perceptron (MLP) networks are particularly helpful in the study on this type of issues $[12,20]$. 


\section{Crashworthiness indicator}

The main coefficient of effectiveness is the energy dissipation that occurs during the dynamic crushing process.

$$
E A=\int_{0}^{d} F(x) d x,[J]
$$

Another coefficient describing the energy absorber is SEA, which represents the energy absorbed in relation to the total mass of the model described by the formula below:

$$
S E A=\frac{E A}{m},\left[\frac{J}{k g}\right]
$$

The MCF (Figure 1) represents the average crushing force that occurs during crushing:

$$
M C F=\frac{E A(d x)}{d x},[N]
$$

Peak Crushing Force (Figure 1), is the maximum force that appears during crushing. When designing the energy absorber, an attempt was made to reduce its value and bring the Mean Crushing Force closer. The last factor determines the relationship between the two forces shown above and is described by the formula:

$$
C L E=\frac{M C F}{P C F} * 100 \%,[-]
$$

\section{Numerical analysis}

The test sample has a profile with a square cross-section. The dimensions are shown in Figure 2. The sample had a fixed length of $200 \mathrm{~mm}$. The material model is aluminium, described as elastic plastic. The length of the porous

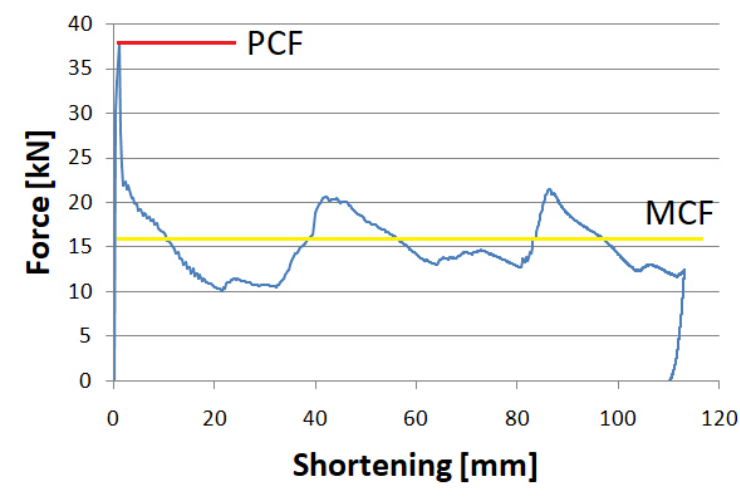

Fig. 1. Exemplary force-shortening diagram of a thin-walled structure material filling was a variable parameter, and it was described in Figure 2 as $\mathrm{X}$, which changed its value every $20 \mathrm{~mm}$, from 40 to 200 . The material used for the filling is ALPORAS foamed aluminium with the parameters shown in Table 1.

The material model created in the Abaqus software suite for aluminium foam in the plastic range is Crushable foam. The elastic material range has been carried out using the Young module and Poisson's ratio. The parameters used for the modelling are shown in Table 1.

Three types of finite element were used in the numerical analysis. The first one is C3D8R and was assigned to the foam element. The next is S4R, which is a deformable shell element that corresponds to a square profile. This type of finite element refers to C3D8R and has been assigned to the foam element. The last used type of element is R3D4 for shell rigid parts. This type of finite element corresponds to the non-deformable plates serving as the base for the profile and the top tup. All the discredited model has a mesh of size 4 .

The numerical analysis was performed in two steps. Firstly, the buckling form was determined for the sample with the specified trigger. Next, the buckling mode was implemented for the dynamic analysis. The thin-walled profile was loaded with 1700J. The mechanical energy was defined by the tup speed $(7 \mathrm{~m} / \mathrm{s})$ and its mass $(70 \mathrm{~kg})$. The specimen was fixed with a non-deformable plate attached to the profile base. The reference point made on the plate had all translational and rotational degrees of freedom blocked. The dynamic analysis was carried out until the tup lost its whole velocity. Then, on the basis of data determined for 1000 points, force-shortening charts were generated.

\section{RESULTS}

The numerical analysis carried out for the profiles with a round trigger and foam filling was compared with an empty control model. The results are shown in the Force-Shortening diagram below. The course of the curves shows that the increase in the length of the foam material has a positive effect on the energy absorption coefficients. The increase in absorber efficiency (CLE) from $39 \%$ to $56 \%$ is mainly due to an increase in the mean crushing force. A reduction of the maximum crushing force contributes to this to a much lesser degree. 
a)

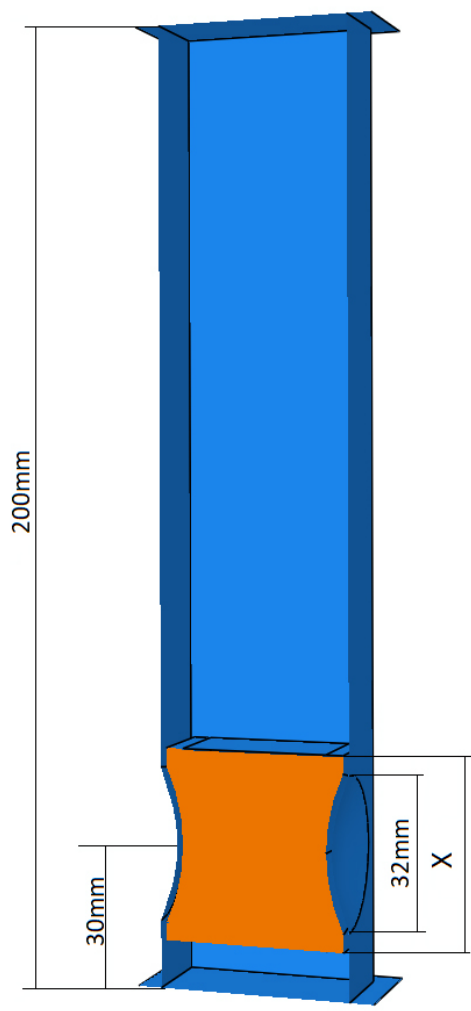

b)

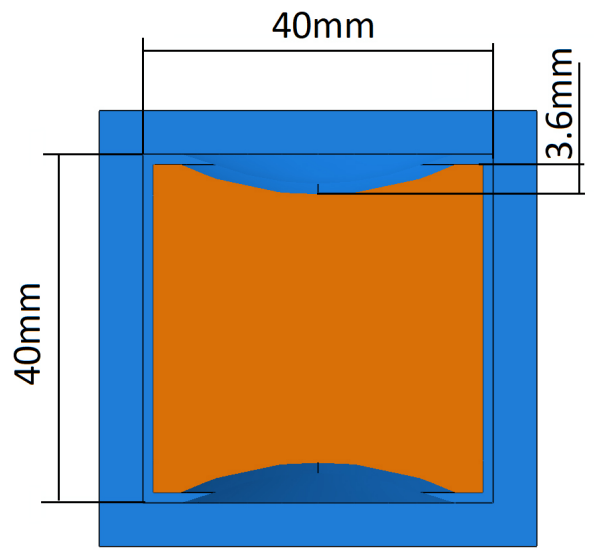

Fig. 2. Dimensions of the tested model

In the case of mean crushing force, a large increase is visible for foam lengths above $80 \mathrm{~mm}$. At a later stage, the MCF value maintains linear progression. The value of the mean crushing force varies by $6 \mathrm{kN}$ between extreme models, which is about $35 \%$ of the profit. A large profit is observed between the models with 60 and $80 \mathrm{~mm}$ filling length. The change of force is about $4 \mathrm{kN}$ which translates into $25 \%$ gain.

All the data presented in Figures 5-8 were approximated by a linear function. The value of the function is shown in the diagram. The PCF value does not show great variability. The fluctuation of force does not exceed 5\%. The elongation of the foam filling has no significant effect on the maximum force detected during crushing.
The total length of the sample changes significantly due to the elongated foam filling. The STE coefficient responsible for the shortening for the extreme values has changed by $40 \%$, i.e. about $30 \mathrm{~mm}$.

The regression algorithm has been used to determine the values using neural networks. Initially, the input and output data were determined. Then, the weights for neurons in certain networks were determined, based on which the neural networks can predict the output values for new input data.

Three MLP networks with the values shown in Table 2 were determined to indicate the values of crushing coefficients. Using neural networks, the values for foams of lengths $30,50,70,90$, $110,130,150,170,200 \mathrm{~mm}$ were analysed. The

Table 1. Material data for Abaqus software

\begin{tabular}{|l|c|l|c|}
\hline \multicolumn{2}{|c|}{ Al-6061 aluminium material properties } & \multicolumn{2}{c|}{ ALPORAS Foam material properties } \\
\hline Density $\left[\mathrm{kg} / \mathrm{m}^{3}\right]$ & 2700 & Density $\left[\mathrm{kg} / \mathrm{m}^{3}\right]$ & 270 \\
\hline Young Modulus $[\mathrm{MPa}]$ & 70000 & Young's Modulus [MPa] & 60 \\
\hline Poisson ratio v [-] & 0.33 & Poisson's Ratio [-] & 0.33 \\
\hline Yield point $\mathrm{R}_{\mathrm{e}}[\mathrm{MPa}]$ & 200 & Yield strength (compression) [MPa] & 1.702 \\
\hline Tensile Strength $\mathrm{R}_{\mathrm{m}}[\mathrm{MPa}]$ & 279.98 & Poisson's Plastic Ratio [-] & 0.015 \\
\hline Elongation A\% [\%] & 5.98 & \multicolumn{1}{c|}{-} \\
\hline
\end{tabular}


a)

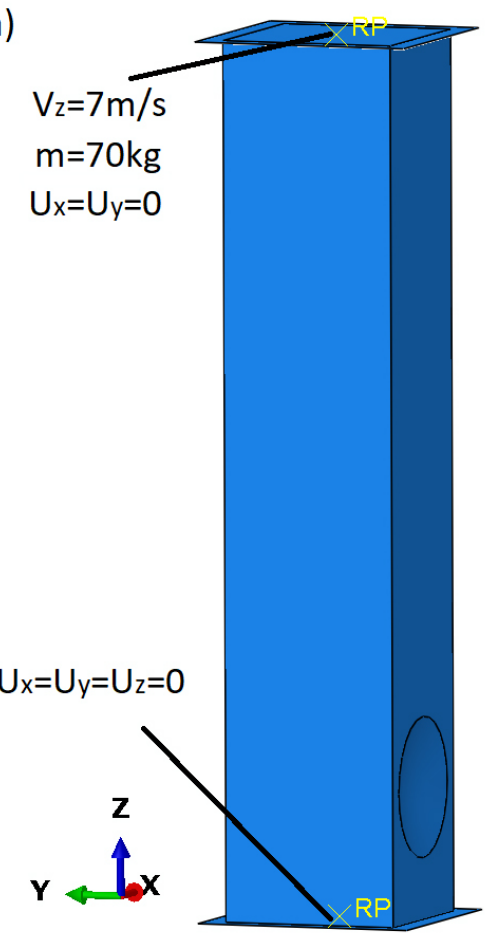

b)

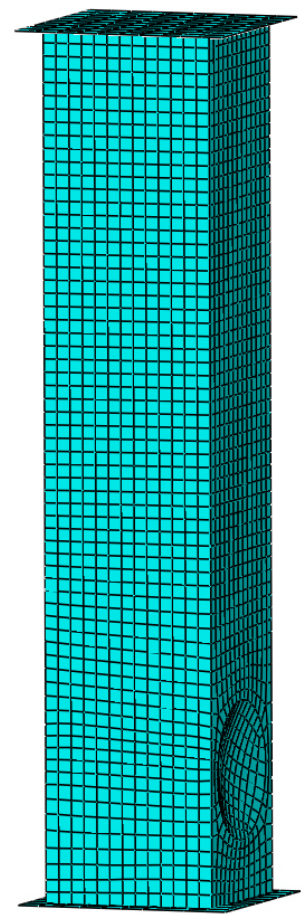

Fig. 3. Numerical analysis a) boundary condition b) discretized model

a) Aluminium foam

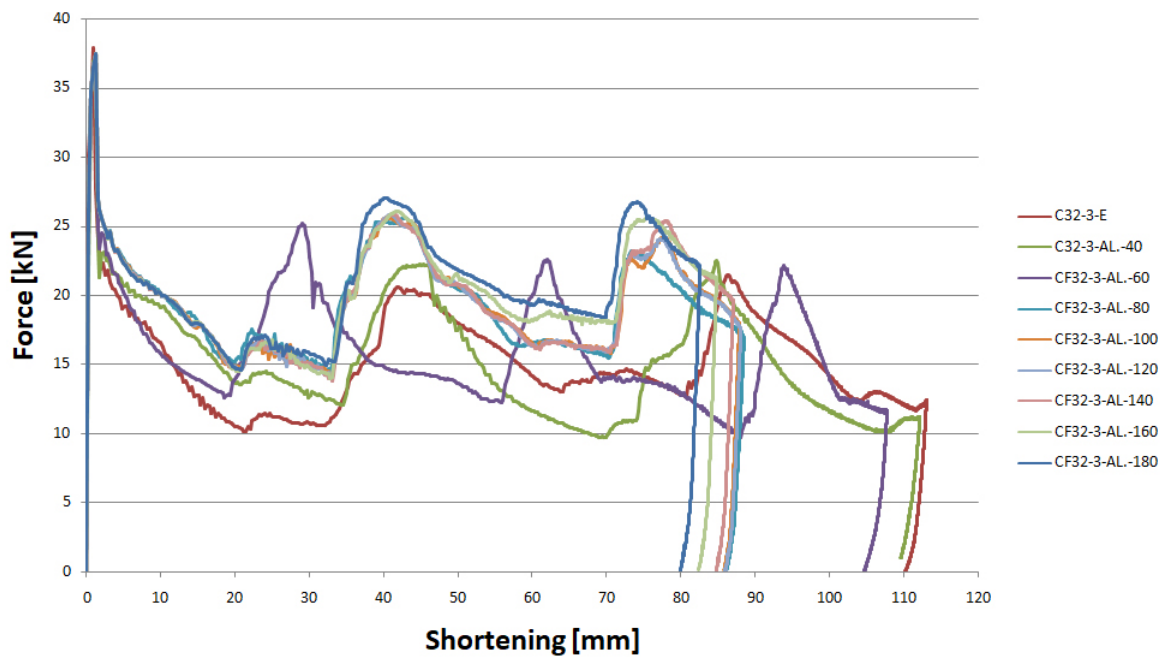

b)
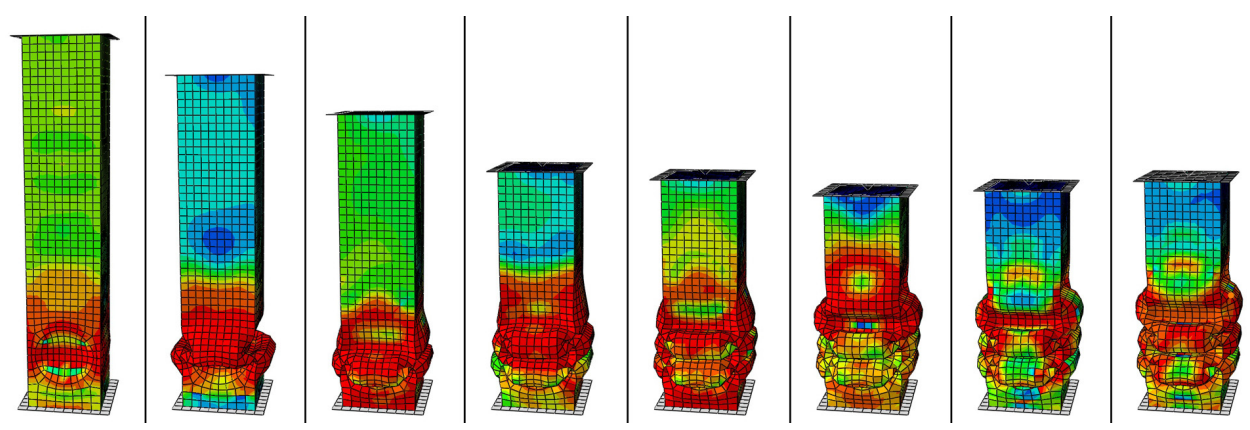

Fig. 4. Force-shortening diagram and stages of dynamic analysis for tested model 


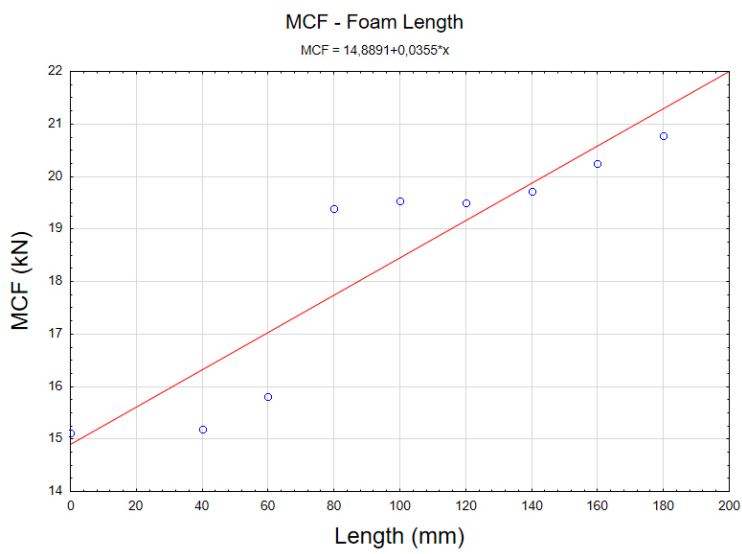

Fig. 5. MCF dependence on the aluminium foam length

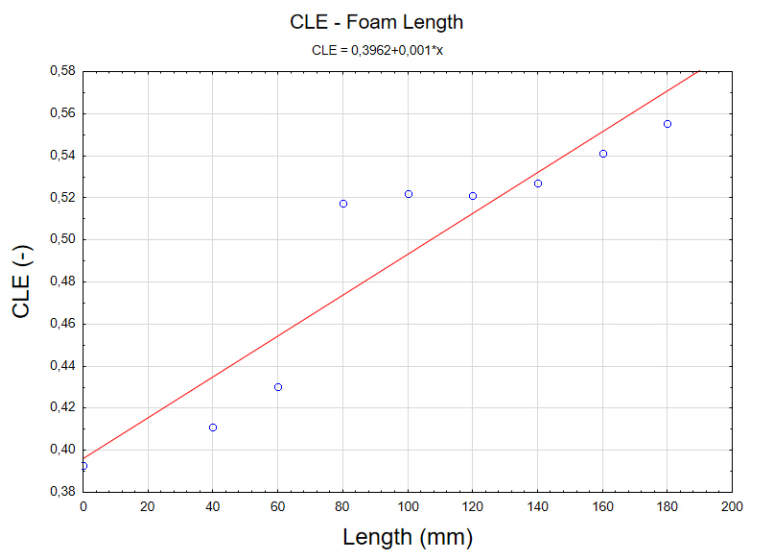

Fig. 7. Diagram of the CLE - foam length dependence

force values determined by the networks are presented below in Figure 9.

The mean force values determined by the neural networks correspond to the characteristics obtained from the numerical analyses. The results of the analyses show a clear connection between the foam filling length and the mean crushing force (MCF) value.

The values obtained by using the three neural networks presented in the table above are the same as those obtained during the numerical analysis. The data confirm the behaviour of the

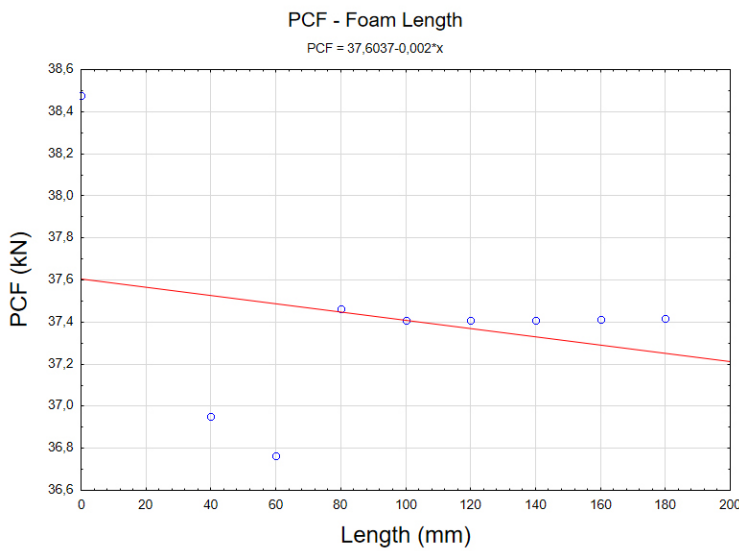

Fig. 6. PCF dependence on the aluminium foam length

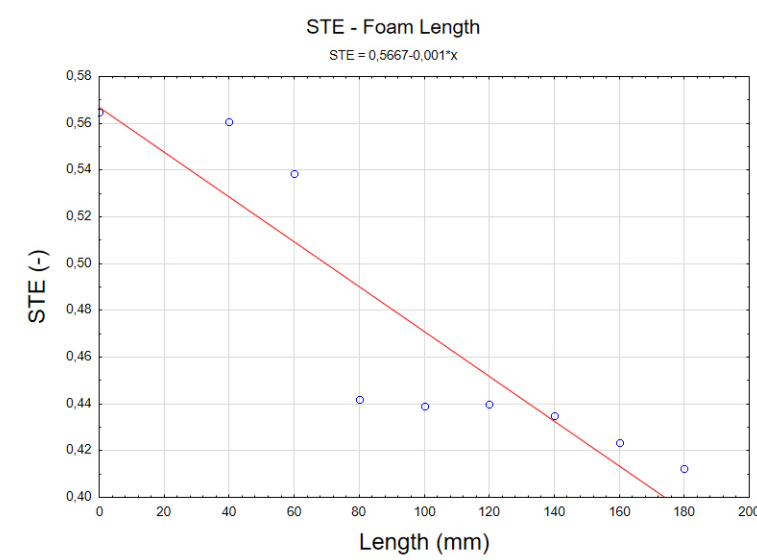

Fig. 8. Diagram of the STE - foam length dependence

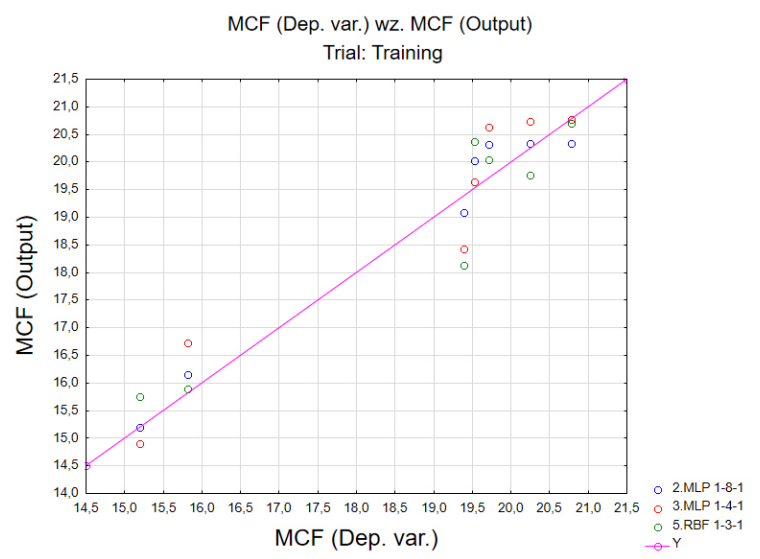

Fig. 9. Predicted values of Mean Crushing Force.

Table 2. Quality of MLP neural network models

\begin{tabular}{|c|c|c|c|c|c|c|}
\hline Network & $\begin{array}{c}\text { Quality } \\
\text { (Training) }\end{array}$ & Error (training) & $\begin{array}{c}\text { Learning } \\
\text { algorithm }\end{array}$ & Error & $\begin{array}{c}\text { Activation } \\
\text { (hidden) }\end{array}$ & $\begin{array}{c}\text { Activation } \\
\text { (Output) }\end{array}$ \\
\hline MLP 1-8-1 & 0.984024 & 0.073614 & BFGS 27 & SOS & Exponential & Logistic \\
\hline MLP 1-4-1 & 0.955194 & 0.210583 & BFGS 0 & SOS & Exponential & Tanh \\
\hline RBF 1-3-1 & 0.949377 & 0.208209 & RBFT & SOS & Gaussa & Linear \\
\hline
\end{tabular}


Table 3. The predicted MCF values for different foam lengths

\begin{tabular}{|c|c|c|c|}
\hline 1.MCF_(t) & 2.MCF_(t) & 3.MCF_(t) & Length $(\mathrm{mm})$ \\
\hline 15.19574 & 14.07514 & 16.59678 & 30.0000 \\
\hline 15.32130 & 15.81046 & 15.49232 & 50.0000 \\
\hline 17.82577 & 17.62527 & 16.86175 & 70.0000 \\
\hline 19.71846 & 19.11005 & 19.41054 & 90.0000 \\
\hline 20.17282 & 20.04534 & 20.83522 & 110.0000 \\
\hline 20.29957 & 20.50972 & 20.47357 & 130.0000 \\
\hline 20.33799 & 20.69792 & 19.75989 & 150.0000 \\
\hline 20.34659 & 20.76160 & 20.10824 & 170.0000 \\
\hline 20.34145 & 20.78257 & 22.17560 & 200.0000 \\
\hline
\end{tabular}

foam filling. The length of the foam above $80 \mathrm{~mm}$ significantly increases the mean crushing force. not affect the value of peak crushing force, which is a very important aspect in passive safety.

\section{CONCLUSIONS}

The crushing coefficients were determined for thin-walled profiles of square section with a constant circular trigger. The aluminium foam filling changed its length from $40 \mathrm{~mm}$ to $180 \mathrm{~mm}$. Using neural networks, the MCF was determined for values between $30 \mathrm{~mm}, 50 \mathrm{~mm}, 70 \mathrm{~mm}, 90 \mathrm{~mm}$, $110 \mathrm{~mm}, 130 \mathrm{~mm}, 150 \mathrm{~mm}, 170 \mathrm{~mm}, 200 \mathrm{~mm}$. The results showed the smallest influence of the length of the filling on the value of maximum crushing force. The largest difference between the values was less than $5 \%$. The MCF, CLE, STE coefficients show much larger fluctuations. CLE varies from $39 \%$ to $56 \%$. The variation between CLE for extreme values is about $41 \%$. This means that the length of the foam filling has a very large impact on the energy efficiency of the absorber. The total efficiency of the absorbers was raised by increasing the MCF value. Longer aluminium foam resulted in a smaller shortening of the samples during crushing, with the same absorbed mechanical energy $(1700 \mathrm{~J})$. The change in the shortening length is approx. $30 \mathrm{~mm}$, which corresponds to $15 \%$ of the initial profile length. Despite the reduction in the sample crush time, the total overload does not endanger the human life. The maximum overload during crushing is $25 \mathrm{G}$, but it occurs for a short pulse which is safe for potential vehicle passengers. In this type of analysis, the MLP networks show a very good quality of learning and have a good prediction quality defined for the MCF. The results presented in the paper show a significant influence of the foamed material filling on the increased efficiency of the energy absorber. Moreover, the profile filling did

\section{REFERENCES}

1. Abramowicz W, Jones N (1984) Dynamic axial crushing of square tubes. Int J Impact Eng 2(2):179-208

2. Acar E (2015) Increasing automobile crash response metamodel accuracy through adjusted cross validation error based on outlier analysis. Int J Crashworthiness 20(2):107-122

3. 3Ferdynus M, Kotełko M, Kral J (2018) Energy absorption capability numerical analysis of thinwalled prismatic tubes with corner dents under axial impact. Eksploat i Niezawodn - Maint Reliab 20(2):252-289

4. 4Ferdynus M, Rogala M (2019) Numerical Crush Analysis of Thin-Walled Aluminium Columns with Square Cross-Section and a Partial Foam Filling. Adv Sci Technol Res J 13(3):144-151

5. Gajewski J, Sadowski T (2014) Sensitivity analysis of crack propagation in pavement bituminous layered structures using a hybrid system integrating Artificial Neural Networks and Finite Element Method. Comput Mater Sci 82:114-117

6. Hanssen AG, Langseth M, Hopperstad OS (1999) Static crushing of square aluminium extrusions with aluminium foam filler. Int $\mathrm{J}$ Mech Sci 41(8):967-993

7. Hussain NN, Regalla SP, Rao Yendluri VD (2017) Numerical investigation into the effect of various trigger configurations on crashworthiness of GFRP crash boxes made of different types of cross sections. Int J Crashworthiness 22(5):565-581

8. Kopczyński A, Rusiński E (2010) Passive safety. Energy absorption by thin-walled profiles. Publishing House of the Wrocław University of Technology, Wrocław

9. MacaulayM(1987)IntroductiontoImpactEngineering. Mater Des. doi: 10.1007/978-94-009-3159-6 
10. Meran AP (2016) Solidity effect on crashworthiness characteristics of thin-walled tubes having various cross-sectional shapes. Int J Crashworthiness 21(2):135-147

11. Mohammadiha O, Beheshti $\mathrm{H}$, Aboutalebi FH (2015) Multi-objective optimisation of functionally graded honeycomb filled crash boxes under oblique impact loading. Int $\mathrm{J}$ Crashworthiness 20(1):44-59

12. Pirmohammad S, Esmaeili Marzdashti S (2018) Crashworthiness optimization of combined straight-tapered tubes using genetic algorithm and neural networks. Thin-Walled Struct 127(February):318-332

13. Rogala M, Gajewski J, Ferdynus M (2019) Numerical analysis of the thin-walled structure with different trigger locations under axial load. IOP Conf Ser Mater Sci Eng 710:012028

14. Rózyło P (2019) Passive Safety of a Buggy-Type Car in the Aspect of a Dynamic Analysis of the Frame. Acta Mech Autom 13(2):75-79

15. Vestrum O, Edvard L, Dæhli B, Sture O, Børvik T (2020) Constitutive modeling of a graded porous polymer based on X-ray computed tomography. Mater Des 188(January 2020):108449

16. Wang Z (2019) Recent advances in novel metallic honeycomb structure. Compos Part B Eng. doi: 10.1016/j.compositesb.2019.02.011

17. Wang Z, Jin X, Li Q, Sun G (2020) On crashworthiness design of hybrid metal-composite structures. Int J Mech Sci. doi: 10.1016/j.ijmecsci.2019.105380

18. Wierzbicki T, Abramowicz W (1983) On the Crushing Mechanics of Thin-Walled Structures. J Appl Mech 50(4a):727-734

19. Xie S, Yang W, Li H, Wang N (2017) Impact characteristics and crashworthiness of multi-cell, square, thin-walled, structures under axial loads. Int J Crashworthiness 22(5):503-517

20. Yang S, Qi C (2013) Multiobjective optimization for empty and foam-filled square columns under oblique impact loading. Int J Impact Eng 54:177-191

21. Zhang Y, Ge P, Lu M, Lai X (2018) Crashworthiness study for multi-cell composite filling structures. Int J Crashworthiness 23(1):32-46 